\title{
Current Data on Lower Prevalence and Age-Related Aggravation of COVID-19 in Japan
}

\author{
Hiroshi Bando ${ }^{1,2^{*}}$ \\ ${ }^{1}$ Tokushima University / Medical Research, Tokushima, Japan \\ ${ }^{2}$ Integrative Medicine Japan (IMJ), Shikoku Island Division, Tokushima, Japan
}

Corresponding Author: Hiroshi BANDO, MD, PhD, FACP ORCID iD

Address: Tokushima University /Medical Research, Nakashowa 1-61, Tokushima 770-0943, Japan. Tel: +81-90-31872485; Email: pianomed@bronze.ocn.ne.jp

Received date: 19 July 2021; Accepted date: 07 August 2021; Published date: 15 August 2021

Citation: Bando H. Current Data on Lower Prevalence and Age-Related Aggravation of COVID-19 in Japan. Asp Biomed Clin Case Rep. 2021 Aug 15;4(2):153-56.

Copyright (C) 2021 Bando $\mathrm{H}$. This is an open-access article distributed under the Creative Commons Attribution License, which permits unrestricted use, distribution, and reproduction in any medium provided the original work is properly cited.

\begin{abstract}
Pandemic COVID-19 has been crucial problem worldwide, and authors have reported less prevalence and excess death in Japan. The Ministry of Health, Labour and Welfare of Japan presented COVID-report of July 2021 Edition. Among them, the number of people diagnosed with COVID-19 in Japan was 796,835 until July 1, 2021, which is equivalent to $0.6 \%$ of the total population. Aggravation rate of COVID-19 increases remarkably with aging. The result shows $1,4,10,25,47,70<$ in 30s, 40s, 50s, 6o, 70s, 80s< years old, respectively. In contrast, it shows $0.5,0.2,0.3$ in $\leq 9,10-19,20-29$ years, respectively.
\end{abstract}

\section{Keywords}

COVID-19, The Ministry of Health, Labour and Welfare of Japan, Severe Acute Respiratory Syndrome Coronavirus 2, Japan, John Hopkins University

\section{Abbreviations}

MHLW: Labour and Welfare of Japan; SARS-CoV-2: Severe Acute Respiratory Syndrome Coronavirus 2

The pandemic COVID-19 has been crucial problem worldwide [1]. Various factors from our lifestyle are involved in this infection [2]. Furthermore, several cohort studies showed several risks related to the aggravation of COVID-19 [3]. They include the influence of obesity, sarcopenia and so on $[4,5]$. Such factors and international comparison would be considered for the management of COVID-19 [6]. The Ministry of Health, Labour and Welfare of Japan published "Current situation of COVID-19 of July 2021 Edition on July 9, 2021 [7]. This is a summary of important clinical points regarding the most recent status regarding COVID-19 and the previous scientific knowledge. It included international comparisons, the number of infected people and deaths and others. Among them, some timely topics are described in this article.

The number of people diagnosed with COVID-19 in Japan was 796,835 until July 1, 2021 [7]. This is equivalent to $0.6 \%$ of the total population. However, there are considerably people without symptoms even if they are infected. Therefore, it does not necessarily represent all infected number of COVID-19 [6]. Among those diagnosed with COVID-19, the percentage of those who become severe state or death was analyzed. 
These results were improved from before (Table-1). Statistic data are present on patients diagnosed after June 2020. The rate of aggravation is about $1.6 \%$ (0.3\% for those in their 50s or younger, 8.5\% in their 60 or older), and the rate of death is about $1.0 \%$ (o.o6\% for those in their 50 or younger, $5.7 \%$ in their 6 os or older) [8].

Statistical analysis was conducted on patients who are more likely to become severely ill. There are differences in different age groups. When the standard level is set to 1.0 in thirties (30s), the aggravation rate of each age group will increase remarkably with aging. As a result, 40s are 4 times, 50s are 10, 6os are 25, 70s are 47, and 8os and over are 70 times or more [7]. Thus, aggravation risk is proved to be increased sharply as advancing age. On the other hand, younger generation showed that 0.5 until 9 years old, 0.2 in 1019 years, 0.3 in 20-29 years. These data are provided by research group of Professor Nishiura of Kyoto University, an authority on representative epidemiology in Japan [9,10].

Among COVID-19 patients, some will be recovered, and others will be exacerbated to severe status. What kind of risk factors are involved in the aggravation of clinical progress? The influencing factors are advancing age, underlying pathologies such as obesity, chronic obstructive pulmonary disease (COPD), chronic kidney disease (CKD), diabetes mellitus (DM), hypertension, atherosclerotic cardiovascular disease (ASCVD), obesity, smoking, inactivity and so on $[4,5,11,12]$.

Table-1: The Ratio of aggravation and death in the patients diagnosed as COVID-19

\begin{tabular}{|c|c|c|c|c|c|c|c|c|c|c|c|c|}
\hline & & o--9 & $\mathbf{1 0 - - 1 9}$ & $\mathbf{2 0 - - 2 9}$ & $\mathbf{3 0 - - 3 9}$ & $\mathbf{4 0 - - 4 9}$ & $\mathbf{5 0 - - 5 9}$ & $\mathbf{6 0 - - 6 9}$ & $\mathbf{7 0 - - 7 9}$ & $\mathbf{8 0 - - 8 9}$ & $\mathbf{9 0 -}$ & Total \\
\hline \multirow{2}{*}{ Ratio of Aggravation } & Jan-Apr, 2020 & 0.69 & 0.9 & 0.8 & 1.52 & 3.43 & 6.4 & 15.25 & 26.2 & 34.72 & 36.24 & 9.8 \\
\cline { 2 - 13 } & Jun-Aug, 2020 & 0.09 & 0.00 & 0.03 & 0.09 & 0.54 & 1.47 & 3.85 & 8.4 & 14,50 & 16.64 & 1.62 \\
\hline \multirow{2}{*}{ Ratio of Death } & Jan-Apr, 2020 & 0.00 & 0.00 & 0.00 & 0.36 & 0.61 & 1.18 & 5.49 & 17.05 & 30.72 & 34.5 & 5.62 \\
\cline { 2 - 12 } & Jun-Aug, 2020 & 0.00 & 0.00 & 0.01 & 0.01 & 0.1 & 0.29 & 1.24 & 4.65 & 12 & 16.09 & 0.96 \\
\hline
\end{tabular}

The Data are shown in the unit of percentage (\%)

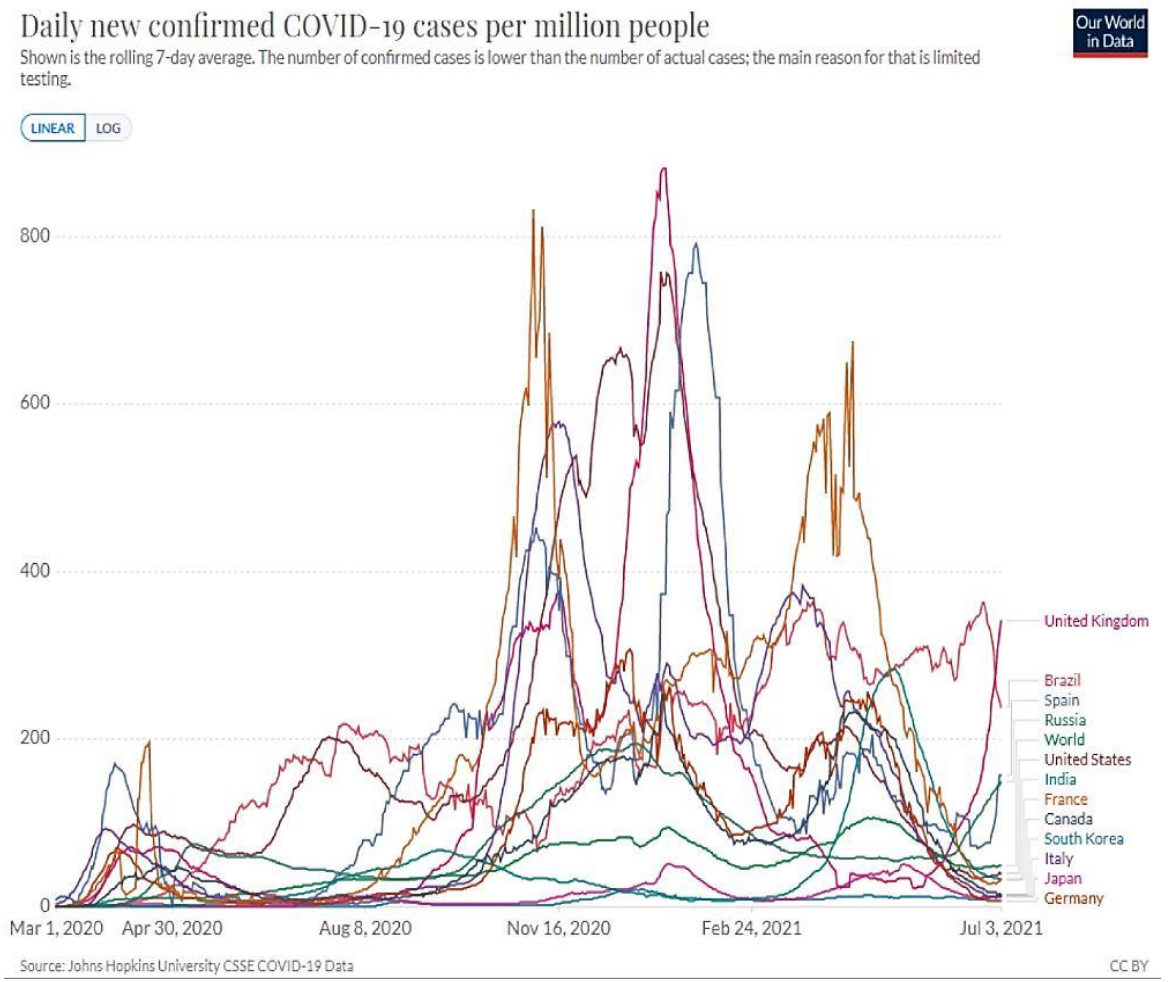


COVID-19 situation was observed using international indicators. The number of infected people and the number of deaths per capita in Japan remains at a low level compared to the global average and major countries [13]. John Hopkins University has always presented COVID-19 statistics daily [14]. Fig-1 shows a comparison of the number of people infected with COVID-19 per million people worldwide in July. These data are from the analysis of the rolling 7-day average. The number of confirmed cases is lower than the actual number of infected cases. The main reason is that the examination for COVID-19 would be limited. Looking at this data, Japan is kept low compared to other countries [15].

Clinical problem for transmission of COVID-19 to others has been drawing attention. Among people who were diagnosed as COVID-19, less than $20 \%$ of them transmit other people. More than $80 \%$ of them do not infect others. Therefore, the pandemic of COVID-19 can be suppressed in the future by paying attention to continuing prevention measures. The clinical effect of wearing a mask has been known [16]. Proper use of masks has been shown to reduce the amount of virus inhaled by those who come into contact with the infected person. The results show $60-80 \%$ reduction when the infected person wears a cloth mask and 20$40 \%$ reduction when other people contacting with the infected person.

In summary, most recent topic of COVID-19 in Japan was described. This article will become hopefully reference data for research development.

\section{Conflict of Interest}

The author has read and approved the final version of the manuscript. The author has no conflicts of interest to declare.

\section{References}

[1] Bando H. Some Measures for COVID-19 Including Deep Ultraviolet Light-Emitting Diode (DUV-LED), Gc protein-derived Macrophage-Activating Factor (Gcmaf), and 5-Aminolevulinic Acid (5-ALA). Asp Biomed Clin Case Rep. 2021 Jun 30;4(2):110-13.

[2] Lim MA, Smith L. COVID-19 pandemic: a wake-up call for lifestyle-related preventable conditions in older adults. Aging Clin Exp Res. 2021 Aug;33(8):2367-68. [PMID: 34155603]

[3] Després JP. Severe COVID-19 outcomes - the role of physical activity. Nat Rev Endocrinol. 2021 Aug;17(8):451-52. [PMID: 34112985]

[4] O'Rourke RW, Lumeng CN. Pathways to Severe COVID-19 for People with Obesity. Obesity (Silver Spring). 2021 Apr;29(4):645-53. [PMID: 33270351]

[5] Lim MA, Kurniawan AA. Dreadful Consequences of Sarcopenia and Osteoporosis due to COVID-19 Containment. Geriatr Orthop Surg Rehabil. 2021 Feb 10;12:2151459321992746. [PMID: 33628613]

[6] Bando H. Fewer Annual Deaths in Japan with Negative Excess Mortality for COVID-19. Asp Biomed Clin Case Rep. 2021 Apr 06;4(1):84-87.

[7] Ministry of Health, Labour and Welfare. Japan: Ministry of Health, Labour and Welfare; 2019. Available from: https://www.mhlw.go.jp/english/

[8] Ito K, Piantham C, Nishiura H. Predicted dominance of variant Delta of SARS-CoV-2 before Tokyo Olympic Games, Japan, July 2021. Euro Surveill. 2021 Jul;26(27):2100570. [PMID: 34240695]

[9] Jung SM, Endo A, Kinoshita R, Nishiura H. Projecting a second wave of COVID-19 in Japan with variable interventions in high-risk settings. R Soc Open Sci. 2021 Mar 31;8(3):202169. [PMID: 34035940]

[10] Nagata S, Nakaya T, Adachi Y, Inamori T, Nakamura K, Arima D, Nishiura H. Mobility Change and COVID-19 in Japan: Mobile Data Analysis of Locations of Infection. J Epidemiol. 2021 Jun 5;31(6):387-91. [PMID: 33814508]

[11] Sallis JF, Adlakha D, Oyeyemi A, Salvo D. An international physical activity and public health research agenda to inform coronavirus disease-2019 policies and practices. J Sport Health Sci. 2020 Jul;9(4):328-34. [PMID: 3245016o]

[12] Hall G, Laddu DR, Phillips SA, Lavie CJ, Arena R. A tale of two pandemics: How will COVID-19 and global trends in physical inactivity and sedentary behavior affect one another? Prog Cardiovasc Dis. 2021 JanFeb;64:108-10. [PMID: 32277997]

[13] Karlinsky A, Kobak D. The World Mortality Dataset: Tracking excess mortality across countries during the COVID-19 pandemic. medRxiv [Preprint]. 2021 Jun 4:2021.01.27.21250604. Update in: Elife. 2021 Jun 30;10: [PMID: 33532789]

[14] John Hopkins University \& Medicine. COVID-19 Dashboard. USA: Centre for Systems Science \& 
Citation: Bando H. Current Data on Lower Prevalence and Age-Related Aggravation of COVID-19 in Japan. Asp Biomed Clin Case Rep. 2021 Aug 15;4(2):153-56.

\section{Editorial}

Engineering; 2021. Available from :

https://coronavirus.jhu.edu/map.html

[15] Woolf SH, Chapman DA, Sabo RT, Zimmerman

EB. Excess Deaths From COVID-19 and Other Causes in the US, March 1, 2020, to January 2, 2021. JAMA. 2021 Apr 2;325(17):1786-89. [PMID: 33797550]

[16] Ueki H, Furusawa Y, Iwatsuki-Horimoto K, Imai M, Kabata H, Nishimura H, Kawaoka Y. Effectiveness of Face Masks in Preventing Airborne Transmission of SARS-CoV-2. mSphere. 2020 Oct 21;5(5):eoo637-20.

[PMID: 33087517]

Keywords: COVID-19, The Ministry of Health, Labour and Welfare of Japan, Severe Acute Respiratory Syndrome Coronavirus 2, Japan, John Hopkins University 